УДК 553.461:549.28

\title{
АКЦЕССОРНАЯ ЗОЛОТО-СЕРЕБРЯНАЯ МИНЕРАЛИЗАЦИЯ ИЗ ХРОМИТИТОВ ХАРЧЕРУЗСКОГО УЛЬТРАМАФИТОВОГО МАССИВА (ПОЛЯРНЫЙ УРАЛ)
}

\author{
Юричев Алексей Николаевич, \\ juratur@sibmail.com \\ Национальный исследовательский Томский государственный университет, \\ Россия, 634050, г. Томск, пр. Ленина, 36.
}

\begin{abstract}
Актуальность исследования обусловлена недостаточной всесторонней изученностью минералогических аспектов ультрамафитовых реститовых массивов, что не дает возможности их обобщения на минералогическом уровне и восстановления полной истории их формирования и преобразования, а также решения целого ряда спорных вопросов петрологии данных объектов. Минералогия акцессорной рудной минерализации из реститовых ультрамафитов является слабо изученным направлением.

Цель: изучение акцессорной золото-серебряной минерализации в массивных (средне- и густовкрапленных) хромититах Харчерузского ультрамафитового массива Полярного Урала, реконструкция механизма ее формирования.

Meтоды: изучение рудной минерализации в аншлифрах с использованием поляризационного микроскопа AxioScope Carl Zeiss; диагностика химического состава рудной минерализации методом рентгеноспектрального микроанализа с применением электронного сканирующего микроскопа Tescan Mira 3 LMU с энергодисперсионным детектором UltimMax100 (Oxford Instruments).

Результаты. Впервые в средне-густовкрапленных хромититах Харчерузского ультрамаффитового массива Полярного Урала диагностирована акцессорная золото-серебряная минерализация, представленная трехкомпонентным твердым раствором $\mathrm{Au}-\mathrm{Cu}-\mathrm{Ag}$, отвечающим по химическому составу медистому золоту (купроауриду), и сульфридом серебра - акантитом ( $\left.A g_{2} S\right)$. Формирование выявленного акантита, очевидно, было связано с наложенными метаморфическими процессами преобразования исходных ультраосновных пород. Однако вопрос генетической природы Au-Cu-Ag трехкомпонентной природной триады не столь однозначен и требует дополнительного, более глубокого изучения. Не исключается, что выявленное в хромититах медистое золото может относиться к первично мантийному типу, в генезисе которого метаморфические коровые процессы, связанные с заимствованием металлов, находящихся в рассеянном виде в реститовых ультрамафитах или вмещающих породах рамы, не играли какой-либо существенной роли. В пользу этого также свидетельствует близкий состав выявленного купроаурида с медистым золотом из хромититов Войкаро-Сыньинского массива, входящего наряду с Харчерузским массивом в состав Хадатинского офиолитового пояса и, очевидно, имеющего с ним общий глубинный мантийный источник.
\end{abstract}

\section{Ключевые слова:}

Полярный Урал, Харчерузский массив, реститовые ультрамафиты, хромититы,

Au-Cu-Ag сплав, акантит, химический состав, генезис.

\section{Введение}

В складчатых структурах Урала сконцентрировано значительное количество проявлений золотосеребряной минерализации, в основном локальных по своим масштабам и сосредоточенных преимущественно в преобразованных породах ультраосновного состава $[1,2]$. Их распространенность характеризуется крайней неравномерностью: преобладающее число проявлений локализовано в массивах альпинотипных ультрамафитов рифейского и раннепалеозойского возрастов, и лишь в незначительном количестве они обнаруживаются в зональных и стратиформных мафит-ультрамафитовых комплексах. Проявления золото-серебряной минерализации в альпинотипных ультрамафитовых массивах наиболее широко распространены на Южном Урале, тогда как на Среднем и Северном Урале они выявлены в единичных объектах Однако при этом в последних широко проявлена промышленная группа золотоносных россыпей водотоков, дренирующих склоны ультрамафитовых тел [3].

Находки же минералов золота и серебра в рудных хромитах реститовых ультрамафитов являются явлением крайне редким, характеризующимся до настоящего времени слабой изученностью и неоднозначной генетической интерпретацией. Последнее обстоятель- ство преимущественно связано с ограниченным аналитическим заделом по химизму данных рудных минералов, обусловленным сложностью их поиска и последующего анализа (микроскопические размеры (до $\sim 10$ мкм) выделений и незначительные (до 0,1 \%) содержания)

В настоящей статье показана акцессорная золотосеребряная минерализация, впервые обнаруженная и проинтерпретированная методом рентгеноспектрального микроанализа автором в массивных (средне- и густовкрапленных) хромититах Харчерузского ультрамафитового массива Полярного Урала.

\section{Геологическая характеристика объекта исследования}

Реститовый ультрамафитовый Харчерузский массив, наряду с ультрамафитовыми массивами Рай-Из, Войкаро-Сыньинский и Сыум-Кеу, формирует Хадатинский офиолитовый пояс, заканчивающий на севере цепочку офиолитовых комплексов Полярного Урала (рис. 1).

Морфологически массив представляет собой пластинообразное тело субширотного простирания протяженностью $\sim 18$ км, при максимальной ширине $\sim 7$ км (в западной части), разделенное в центральной части субмеридиональным разломом северо-восточного про- 
стирания на западный и восточный блоки. Характер контактов реститовых ультрамафитов с вмещающими породами повсеместно тектонический. Породы вмещающей рамы в основном представлены амфиболи- тами и пироксенсодержащими амфиболитами (реже); с северо-запада и на юго-востоке - к ультрамафитам непосредственно примыкают метаморфизованные (соссюритизированные) габбро.

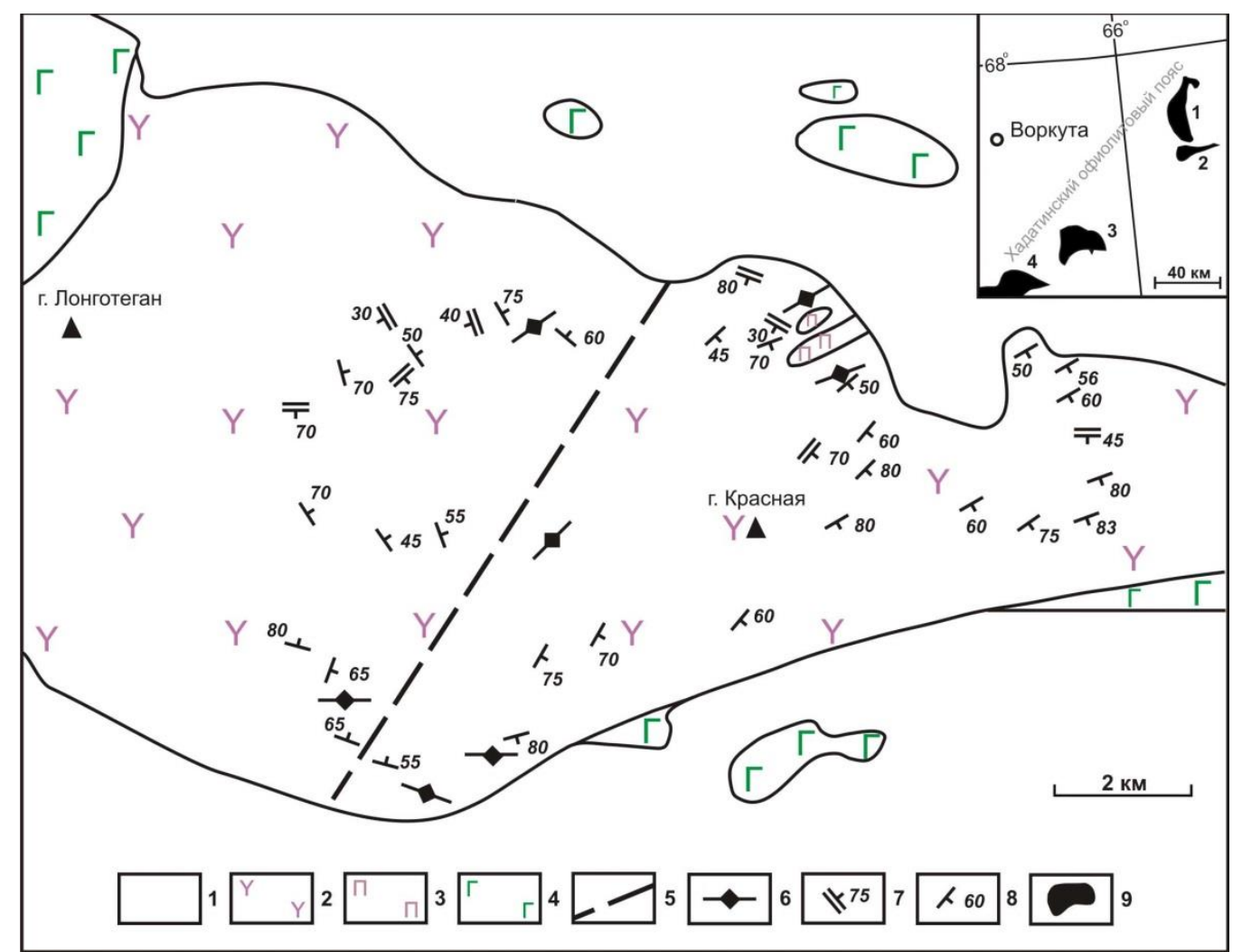

Рис. 1. Схематизированная геологическая карта Харчерузского массива и его географическое положение (врезка) 6 структуре Полярного Урала [4]. 1 - четвертичные отложения; 2 - дуниты, гарибургитыл; 3 - верлиты, клинопироксениты; 4 -габброиды; 5 - разлом; 6-8- элементы залегания: 6 -хромитовых тел, 7 - уплощенности зерен оливина, 8 - кливажа пластического течения; 9 - массивы ультрамафитов: 1 - Сыум-Кеу, 2 Харчерузский, 3 - Рай-Из, 4 - Войкаро-Сыньинский

Fig. 1. Schematized geological map of the Kharcheruz massif and its geographical position (inset) in structure of the Polar Urals [4]. 1 - Quaternary deposits; 2 -dunites, harzburgites; 3 -wehrlites, clinopyroxenites; 4 - gabbroides; 5 fault; 6-8-elements of occurrence: 6 - chromite bodies, 7 -flattened olivine grains, 8 - cleavage of plastic flow; 9 -ultramafic massifs: 1 -Syum-Keu, 2 -Kharcheruzsky, 3 -Rai-Iz, 4 - Voikaro-Synyinsky

В петрографическом отношении Харчерузский массив представлен преимущественно рестированными дунитами и их серпентинизированными разностями, среди которых в западной части массива иногда отмечаются уцелевшие реликтовые линзы гарцбургитов, а также мелкие тела габброидов, обычно интенсивно метасоматически измененные. В экзоконтактовых зонах последних нередко обнаруживаются верлиты и клинопироксениты, которые, как установлено ранее, являются отражением высокотемпературных реакционно-метасоматических процессов [4].

В рестированных дунитах обнаружены ориентированные линзообразные тела хромититов, которые нередко группируются в рудные зоны, характеризующиеся преимущественно субширотным простиранием. Протяженность отдельных тел обычно не превышает $\sim 10$ м при мощностях до $\sim 1$ м. Количество хромшпинелидов значительно варьирует от 10 до $50 \ldots 90 \%$, с образованием от убоговкрапленных до густовкрапленных и сливных рудопроявлений [5].
Для хромититов характерны повышенные содержания платиноидов, детальная характеристика распределения которых дана в работе [6]

\section{Методика исследования}

Для решения поставленных в работе задач применен классический подход минераграфического изучения акцессорных рудных минералов с диагностикой их химического состава методом рентгеноспектрального микроанализа с использованием растровой электронной микроскопии [7]. Изучение отдельных акцессорных рудных зерен и их агрегатов выполнено на сканирующем электронном микроскопе Tescan Mira 3 $\mathrm{LMU}$, интегрированном с системой рентгеновского энергодисперсионного микроанализа UltimMax100 (Oxford Instruments) в ЦКП «Аналитический центр геохимии природных систем» ТГУ (г. Томск), аналитик Е.В. Корбовяк.

Перед непосредственным исследованием на сканирующем микроскопе из представительных образцов средне- 
и густовкрапленных хромититов были изготовлены плоскопараллельные аншлифы толщиной 3...4 мм, с последующим нанесением на их отполированные поверхности тонкого слоя углерода ( 25...30 нм).

Измерения проводились на вольфрамовом катоде при ускоряющем напряжении 20 кВ, текущем токе 15 нА и времени набора спектра 80 с. Диаметр пучка зонда $\sim 2$ мкм. В качестве эталонов сравнения применялись стандарты MAC (55 Standard Universal Block Layout+F/Cup № 6835).

\section{Анализ полученных результатов}

Изучение акцессорной благороднометальной минерализации выполнено в средне- и густовкрапленных хромититах, отобранных из линзообразных рудных тел среди рестированных дунитов Харчерузского ультрамафитового массива. Отобранные образцы хромититов сложены мелко-среднезернистым (0,5 ...3,0 мм) агрегатом зерен хромшпинелидов, сопровождающихся небольшим количеством вторичных силикатов, представленных преимущественно лизардит-антигоритовой ассоциацией и киммереритом (хромсодержащим хлоритом). Хромшпинелиды по химическому составу соответствуют преимущественно хромитам и, в меньшей степени, субферрихромитам. Они умеренновысокохромисты $\left(\mathrm{Cr}_{2} \mathrm{O}_{3} \sim 53 . .65 \%\right)$ при магнезиальности $(\mathrm{MgO} \sim 5 . .9 \%)$ и глиноземистости $\left(\mathrm{Al}_{2} \mathrm{O}_{3} \sim 3 \ldots 8 \%\right)$.
Учитывая микроскопические выделения изучаемой минерализации, ее обнаружение и диагностика представились возможными только путем трудоемкого детального изучения всей рабочей поверхности аншлифов хромититов под микроскопом. В процессе исследования автором впервые установлены трехкомпонентный твердый раствор $\mathrm{Au}-\mathrm{Cu}-\mathrm{Ag}$, соответствующий по химическому составу медистому золоту (купроауриду), и сульфид серебра - акантит $\left(\mathrm{Ag}_{2} \mathrm{~S}\right)$. Они в основном отмечаются в виде редких обособленных зерен размером первые микроны (максимально до 10 мкм), приуроченных, преимущественно, к мелким трещинкам и зонкам кавернозности внутри зерен хромшпинелидов.

Трехкомпонентные природные сплавы $\mathrm{Au}-\mathrm{Cu}-\mathrm{Ag}$ имеют неправильную комковатую форму, с вмятопластичной и чешуйчатой скульптурой отдельных индивидов (рис. 2, $a-2$ ). В их химическом составе существенно преобладают два компонента: золото $(54,9 \ldots 62,9 \%)$ и медь $(29,5 \ldots 38,1 \%)$, а серебро отмечается в виде постоянной примеси $(5,4 \ldots 8,7 \%)$ (табл. 1). При этом отмечено, что при достаточно широких границах смесимости золота и меди практически всегда сохраняется их пропорциональное соотношение, стремящееся к $\mathrm{Au} / \mathrm{Cu}=2 / 1$. В отношении других химических элементов диагностированная природная триада характеризуется «стерильностью».
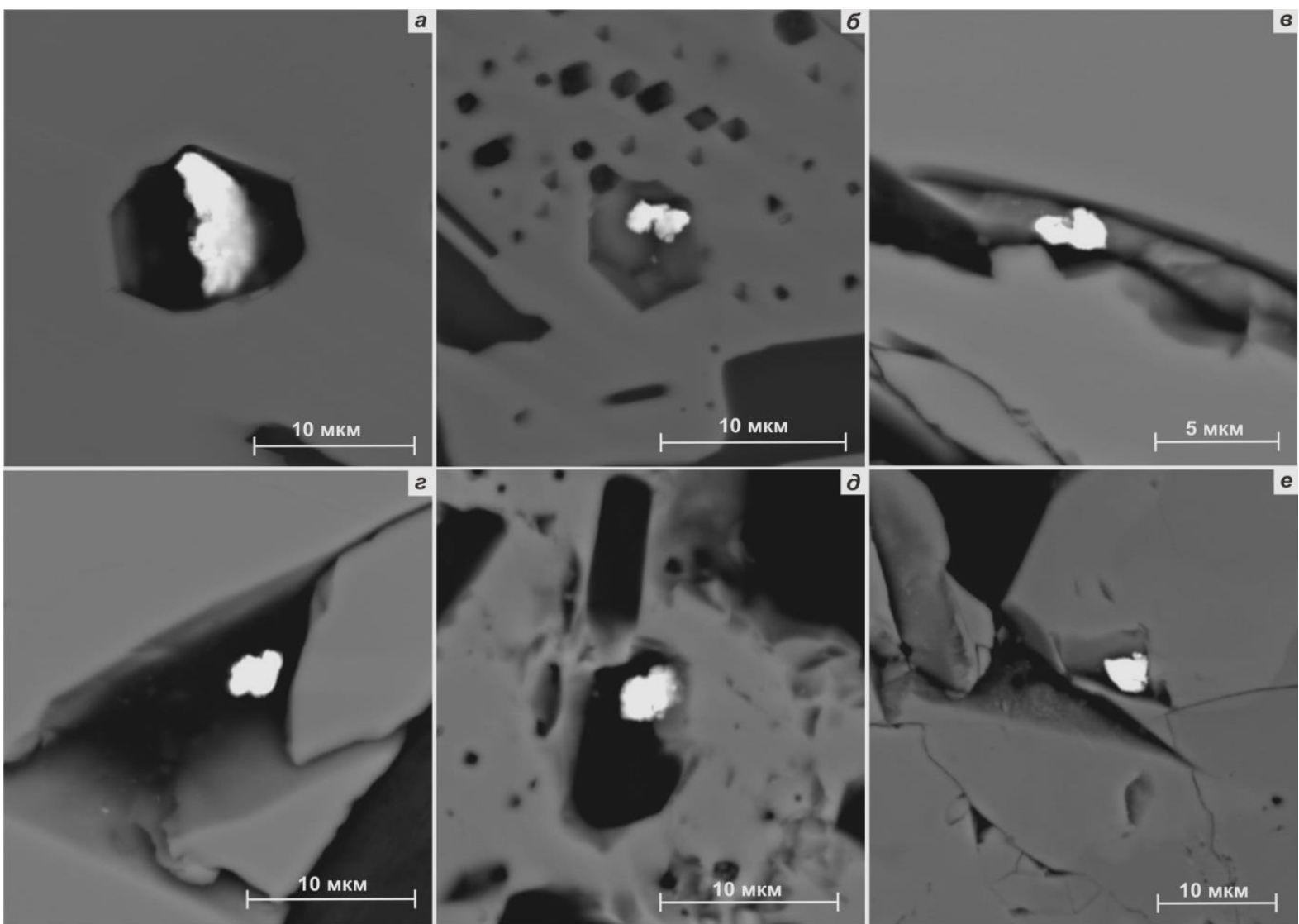

Рис. 2. Микровключения трехкомпонентного твердого раствора $A u-C u-A g(a-2)$ и акантита (д, e) в хромитовой матрице (серое) густовкрапленных хромититов из Харчерузского ультрамафитового массива. Изображения в обратно-отраженных электронах

Fig. 2. Microinclusions of three-component solid solutions of $A u-C u-A g(a-2)$ and acanthite $(\partial, e)$ in chromite matrix (gray) of densely disseminated chromitites from Kharcheruz ultramafic massif. BSE images 
Таблица 1. Химический состав медистого золота из хромититов Харчерузского ультрамафитового массива, вес. \%

Table 1. Chemical composition of cuprous gold from chromitites of the Kharcheruz ultramafic massif, wt. \%

\begin{tabular}{|c|c|c|c|c|c|}
\hline Образец/Sample & $\mathrm{Au}$ & $\mathrm{Cu}$ & $\mathrm{Ag}$ & Cyммa/Sum & Формула/ Formula \\
\hline $\mathrm{X}_{3} 15 / 1-16-284$ & 56,56 & 36,51 & 6,26 & 99,33 & $\mathrm{Cu}_{0,63} \mathrm{Au}_{0,31} \mathrm{Ag}_{0,06}$ \\
\hline $\mathrm{X}_{3} 15 / 1-16-288$ & 58,14 & 35,40 & 6,58 & 100,12 & $\mathrm{Cu}_{0,61} \mathrm{Au}_{0,32} \mathrm{Ag}_{0,07}$ \\
\hline $\mathrm{K}-26 / 1-7-87$ & 55,22 & 38,09 & 6,64 & 99,95 & $\mathrm{Cu}_{0,64} \mathrm{Au}_{0,30} \mathrm{Ag}_{0,06}$ \\
\hline $3398 / 2-1-217$ & 57,93 & 34,10 & 7,36 & 99,4 & $\mathrm{Cu}_{0,60} \mathrm{Au}_{0,33} \mathrm{Ag}_{0,07}$ \\
\hline $\mathrm{K}-15-2-227$ & 55,02 & 38,07 & 6,03 & 99,12 & $\mathrm{Cu}_{0,64} \mathrm{Au}_{0,30} \mathrm{Ag}_{0,06}$ \\
\hline $\mathrm{K}-15-12-328$ & 60,23 & 30,65 & 7,59 & 98,47 & $\mathrm{Cu}_{0,56} \mathrm{Au}_{0,36} \mathrm{Ag}_{0,08}$ \\
\hline $7-7 / 1-23$ & 58,41 & 32,28 & 7,91 & 98,60 & $\mathrm{Cu}_{0,58} \mathrm{Au}_{0,34} \mathrm{Ag}_{0,08}$ \\
\hline $7-7 / 1-52$ & 58,63 & 32,67 & 8,29 & 99,59 & $\mathrm{Cu}_{0,58} \mathrm{Au}_{0,33} \mathrm{Ag}_{0,09}$ \\
\hline $7-7 / 1-57$ & 59,99 & 31,52 & 8,75 & 100,26 & $\mathrm{Cu}_{0,56} \mathrm{Au}_{0,35} \mathrm{Ag}_{0,09}$ \\
\hline $\mathrm{X}_{3} 15 / 4-71$ & 60,18 & 32,62 & 5,76 & 98,57 & $\mathrm{Cu}_{0,59} \mathrm{Au}_{0,35} \mathrm{Ag}_{0,06}$ \\
\hline $\mathrm{X}_{3} 15 / 4-86$ & 61,86 & 33,25 & 7,10 & 102,21 & $\mathrm{Cu}_{0,57} \mathrm{Au}_{0,35} \mathrm{Ag}_{0,08}$ \\
\hline $\mathrm{X}_{3} 15 / 4-95$ & 60,43 & 30,51 & 8,35 & 99,29 & $\mathrm{Cu}_{0,56} \mathrm{Au}_{0,35} \mathrm{Ag}_{0,09}$ \\
\hline $\mathrm{X}_{3} 15 / 4-96$ & 59,67 & 30,64 & 8,39 & 98,7 & $\mathrm{Cu}_{0,56} \mathrm{Au}_{0,35} \mathrm{Ag}_{0,09}$ \\
\hline $\mathrm{X}_{3} 15 / 4-100$ & 59,77 & 32,62 & 7,32 & 99,71 & $\mathrm{Cu}_{0,58} \mathrm{Au}_{0,34} \mathrm{Ag}_{0,08}$ \\
\hline $\mathrm{X}_{3} 15 / 4-116$ & 62,90 & 31,60 & 7,31 & 101,81 & $\mathrm{Cu}_{0,56} \mathrm{Au}_{0,36} \mathrm{Ag}_{0,08}$ \\
\hline $\mathrm{X}_{3} 15 / 4-117$ & 58,57 & 33,41 & 8,24 & 100,22 & $\mathrm{Cu}_{0,59} \mathrm{Au}_{0,33} \mathrm{Ag}_{0,08}$ \\
\hline $\mathrm{X}_{3} 15 / 4-120$ & 58,04 & 33,65 & 8,28 & 99,97 & $\mathrm{Cu}_{0,59} \mathrm{Au}_{0,33} \mathrm{Ag}_{0,08}$ \\
\hline $\mathrm{X}_{3} 15 / 4-121$ & 58,12 & 33,67 & 7,61 & 99,4 & $\mathrm{Cu}_{0,59} \mathrm{Au}_{0,33} \mathrm{Ag}_{0,08}$ \\
\hline $\mathrm{X}_{3} 15 / 4-122$ & 58,57 & 33,66 & 7,48 & 99,71 & $\mathrm{Cu}_{0,59} \mathrm{Au}_{0,33} \mathrm{Ag}_{0,08}$ \\
\hline
\end{tabular}

Прослежена закономерность по взаимному сонахождению выявленного медистого золота с минералами элементов платиновой группы (ЭПГ) - сульфидами лаурит-эрликманитового ряда с преимущественно осмиевой специализацией. При этом в последних также постоянно диагностируется незначительное количество меди в составе (до 2,9\%).
Акантит отмечается в виде единичных мелких таблитчатых выделений размером не более 4 мкм (рис. 2,, , е). В его составе нередко диагностируется изоморфная к серебру примесь железа (до 1,4 \%) (табл. 2). В отношении остальных элементов минерал является «стерильным».

Таблица 2. Химический состав акантита из хромититов Харчерузского ультрамафитового массива, вес. \%

Table 2. Chemical composition of acanthite from chromitites of the Kharcheruz ultramafic massif, wt. \%

\begin{tabular}{|c|c|c|c|c|c|}
\hline Образец/Sample & $\mathrm{Ag}$ & $\mathrm{Fe}$ & $\mathrm{S}$ & Сумма/Sum & Формула/ Formula \\
\hline $\mathrm{K}-15-7-269$ & 87,22 & - & 12,34 & 99,56 & $\mathrm{Ag}_{2,10} \mathrm{~S}_{0,90}$ \\
\hline $\mathrm{K}-15-10-321$ & 86,73 & - & 12,95 & 99,68 & $\mathrm{Ag}_{1,99} \mathrm{~S}_{1,01}$ \\
\hline $\mathrm{K}-15-10-322$ & 86,22 & - & 13,34 & 99,56 & $\mathrm{Ag}_{1,92} \mathrm{~S}_{1,08}$ \\
\hline $\mathrm{K}-15-11-324$ & 84,97 & 1,30 & 13,75 & 100,03 & $\left(\mathrm{Ag}_{1,85} \mathrm{Fe}_{0,05}\right)_{1,90} \mathrm{~S}_{1,10}$ \\
\hline $\mathrm{K}-15-11-325$ & 85,64 & 1,43 & 13,69 & 100,76 & $\left(\mathrm{Ag}_{1,86} \mathrm{Fe}_{0,06}\right)_{1,92} \mathrm{~S}_{1,08}$ \\
\hline $\mathrm{K}-26 / 2-14-193$ & 86,97 & 0,18 & 12,41 & 99,57 & $\left(\mathrm{Ag}_{2,08} \mathrm{Fe}_{0,01}\right)_{2,09} \mathrm{~S}_{0,91}$ \\
\hline $\mathrm{K}-26 / 2-18-213$ & 86,38 & 0,87 & 13,01 & 100,26 & $\left(\mathrm{Ag}_{1,97} \mathrm{Fe}_{0,04}\right)_{2,01} \mathrm{~S}_{0,99}$ \\
\hline $\mathrm{K}-26 / 2-18-214$ & 86,51 & - & 12,76 & 99,27 & $\mathrm{Ag}_{2,01} \mathrm{~S}_{0,99}$ \\
\hline $\mathrm{K}-26 / 2-18-215$ & 86,18 & 0,75 & 12,32 & 99,25 & $\left(\mathrm{Ag}_{2,08} \mathrm{Fe}_{0,03}\right)_{2,11} \mathrm{~S}_{0,89}$ \\
\hline
\end{tabular}

Отдельные химические анализы минерала показывают завышенную роль серебра в составе (до $90 \%$ ). Подобная тенденция, очевидно, связана с наличием в более крупных выделениях акантита микроскопических включений самородного серебра. Подобный парагенезис часто отмечается в сульфидных серебросодержащих рудах как продукт проявления эпимагматических гидротермальных процессов $[8,9]$.

Автором также отмечена пространственная связь по взаимному сонахождению акантита и минералов ЭПГ: все образцы, в которых выявлялся акантит, содержали акцессорные зерна платиноидов.

Таким образом, принимая вышеизложенное, первичные химические характеристики трехкомпонентного твердого раствора (количественные содержания элементов-примесей и их соотношение в составе описанных медистых золотин) могут нести ценную информацию о специфике состава родоначального рестита и обстановке физико-химической среды, а также выступать в качестве своеобразных маркерных меток при сравнительном анализе хромититов и вмещающих их реститовых уль- трамафитов из аналогичных объектов на данной территории и в пределах других складчатых провинций.

\section{Заключение}

Впервые в массивных (средне- и густовкрапленных) хромититах, отобранных из линзообразных рудных тел среди рестированных дунитов Харчерузского ультрамафитового массива Полярного Урала, диагностирована акцессорная золото-серебряная минерализация, представленная природным твердым сплавом $\mathrm{Au}-\mathrm{Cu}-\mathrm{Ag}$ и акантитом.

По химическому составу и соотношению компонентов выделенная природная триада соответствует медистому золоту (купроауриду), которое обнаруживает значительное сходство с подобными природными сплавами из родингитов золотого месторождения Золотая Гора (Карабашский ультрамафитовый массив, Южный Урал), из хромититов арсенидного никелькобальтового месторождения Бени-Буазера (Марокко) и из хромититов Войкаро-Сыньинского ультрамафитового массива (Полярный Урал) (рис. 3). 


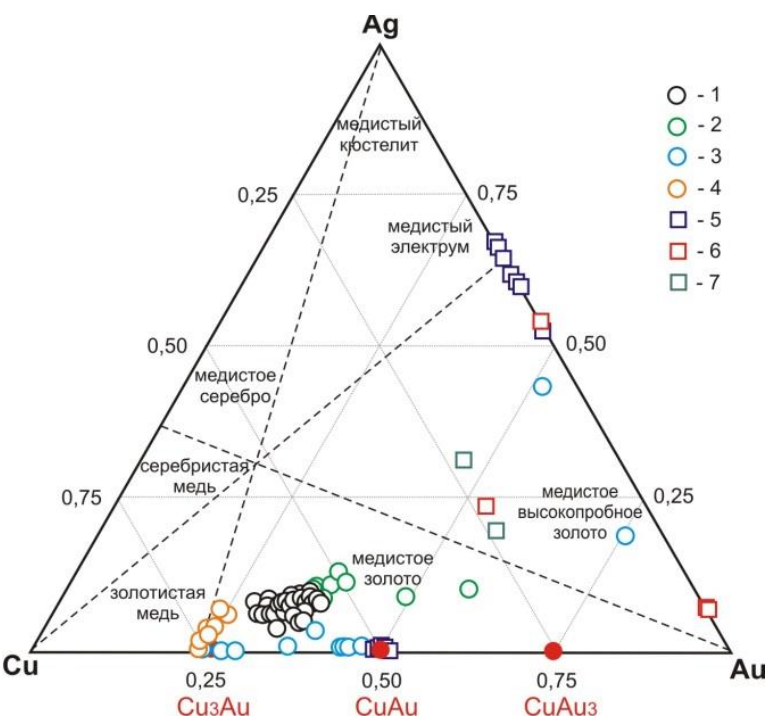

Pис. 3. Тройная диаграмма $C u-A u-A g$ с составами (ат. доли) трехкомпонентных природных сплавов золота, меди и серебра из различных ультрамафитовых объектов. 1 - хромитить Харчерузского ультрамафитового массива (Полярный Урал); 2 - хромитить арсенидного никелькобальтового месторождения Бени-Буазера (Марокко) [10]; 3 - родингиты золотого месторождения Золотая Гора (Карабашский ультрамафитовый массив, Южный Урал) [11, 12]; 4 хромитить Войкаро-Сыньинского ультрамафитового массива (Полярный Урал) [13, 14]; 5 - хромитить и серпентиниты Агардагского ультрамафитового массива (Южная Тува) [15]; 6 - мафит-ультрамафитьл Хурай-Жалгинского массива (Восточньій Саян) [16]; 7-ультрамафить Оспинско-Китойского массива (Восточный Саян) [17, 18]

Fig. 3. Triple diagram $C u-A u-A g$ with compositions (atom fraction) of three-component natural alloys of gold, copper and silver from various ultramafic objects. 1 - chromitites of the Kharcheruz ultramafic massif (Polar Urals); 2 -chromitites of the arsenide nickelcobalt deposit of Beni-Bousera (Morocco) [10]; 3 rodingites of Zolotaya Gora gold deposit (Karabash ultramafic massif, South Urals) [11, 12]; 4 - chromitites of Voikaro-Synyinsky ultramafic massif (Polar Urals) [13, 14]; 5 - chromitites and serpentinites of Agardagsky ultramafic massif (South Tuva) [15]; 6 - mafite-ultramafites of Khurai-Zhalginsky massif (Eastern Sayan) [16]; 7 - ultramafites of OspinskoKitoisky massif (Eastern Sayan) [17, 18]

При этом ранние редкие находки золотин собственно в реститовых ультрамафитах (преимущественно серпентинитах) Южного Урала, Восточного Саяна и Южной Тувы по химическому составу соответствуют электруму или медистому высокопробному золоту и характеризуются либо полным отсутствием меди, либо присутствием последней в существенно меньших количествах, а также частым нали-

\section{СПИСОК ЛИТЕРАТУРЫ}

1. Мурзин М.В. Золотое оруденение в ультрамафитах Урала // Ультрабазит-базитовые комплексы складчатых областей и связанные с ними месторождения: сборник трудов конференции. - Екатеринбург, 2009. - С. 61-64. чием в составе примеси ртути и палладия. Отмечено, что в отдельных ультрамафитовых массивах в акцессорных количествах $\mathrm{Au}-\mathrm{Cu}-\mathrm{Ag}$ сплавы диагностируются как в хромититах, так и во вмещающих их реститовых ультрамафитах. Но последние отличаются по своему химизму. Например, в пределах Агардагского ультрамафитового массива (Южная Тува) в хромититах фиксируется только медистое золото (аурикуприд), а во вмещающих реститовых ультрамафитах - исключительно золотистое серебро (рис. 3). Подобное наблюдение позволяет сделать предположение о тесной генетической связи высокомедистого золота с хромшпинелидами.

Формирование и концентрацию выявленного акантита автор склонен связывать с наложенными метасоматическими (низкотемпературными гидротермальными) процессами преобразования исходных ультраосновных пород. Однако вопрос генетической природы выявленной $\mathrm{Au}-\mathrm{Cu}-\mathrm{Ag}$ трехкомпонентной природной триады не столь однозначен и требует дополнительного более глубокого изучения. На данном этапе однозначно ясно только то, что ее нельзя анализировать обособленно от генетических закономерностей поведения хромшпинелидов и находящихся в тесной ассоциации акцессорных минералов ЭПГ.

Детальный литературный анализ, посвященный генетическим вопросам золотой минерализации в реститовых ультрамафитовых массивах, сводит имеющиеся выводы к единой доминирующей точке зрения о переотложении и локализации такой минерализации в позднюю историю становления массивов альпинотипных ультрамафитов при их метаморфической и метасоматической трансформации [14, 19-24]. Тем не менее автор работы, наряду с другими исследователями [25], не исключает, что выявленные находки медистого золота непосредственно в хромититах могут относиться и к первично мантийному типу, в генезисе которого метаморфические коровые процессы, связанные с заимствованием металлов, находящихся в рассеянном виде в реститовых ультрамафитах или вмещающих породах рамы, не играли какой-либо существенной роли. В пользу этого свидетельствуют высокие концентрации меди в изученной триаде, отражающие высокотемпературный режим ее формирования $[26,27]$, а также близкий состав выявленного медистого золота с медистым золотом из хромититов Войкаро-Сыньинского массива, входящего наряду с Харчерузским массивом в состав Хадатинского офиолитового пояса и, очевидно, имеющих общий глубинный мантийный источник.

Исследование выполнено в рамках гранта по Постановлению Правительства РФ от 09.04.2010 № 220 по договору с Министерством образования и науки РФ от 20.02.2017 № 14.Y26.31.0012.

2. Jones R.S. Gold in igneus, sedimentary and metamorphic rocks. Geological survey circular 610. - Washington: United States Department of the Interior, 1969. - $28 \mathrm{p}$.

3. Мурзин В.В., Суставов С.Г., Мамин Н.А. Золотая и платиноидная минерализация россыпей Верх-Нейвинского массива 
альпинотипных гипербазитов (Средний Урал). - Екатеринбург: УГГГА, 1999. - $93 \mathrm{c}$

4. Чернышов А.И., Юричев А.Н. Структурная эволюция дунитов и хромитов Харчерузского массива (Полярный Урал) // Геотектоника. - 2016. - № 2. - С. 62-77.

5. Юричев А.Н., Чернышов А.И. Хромититы Харчерузского блока массива Сыум-Кеу: вещественный состав и генезис руд (Полярный Урал) // Известия Томского политехнического университета. Инжиниринг георесурсов. - 2016. - Т. 327. № 8. - C. 6-16.

6. Юричев А.Н., Чернышов А.И., Корбовяк Е.В. Платиноносность хромититов Харчерузского ультрамафитового массива (Полярный Урал): новые данные // Записки Российского минералогического общества. - 2020. - Т. 149. - № 3. - С. 38-53.

7. Reed S.J.B. Electron microprobe analysis and scanning electron microscopy in geology. - N.Y.: Cambridge University Press, 2005. $-189 \mathrm{p}$.

8. Юричев А.Н. Акцессорные сульфиды и арсениды из хромититов Эргакского ультрамафитового массива, Западный Саян // Руды и металлы. - 2019. - № 3. - С. 71-79.

9. Yurichev A.N., Chernyshov A.I. New ore minerals from the Kingash ultramafic massif, Northwestern Eastern Sayan // Geology of Ore Deposits. - 2017. - V. 59. - № 7. - P. 626-631.

10. Oen I.S., Kieft C. Nickeline with pyrrhotite and cubanite exsolutions, $\mathrm{Ni}-\mathrm{Co}$ rich loellingite and an $\mathrm{AuCu}$ alloy in $\mathrm{Cr}-\mathrm{N}$ ores from Beni-Bousera, Morocco // Neues Jahrbuch Fur Mineralogie, Monatshefte. - 1974. - P. 1-8.

11. Physicochemical model of formation of $\mathrm{Cu}-\mathrm{Ag}-\mathrm{Au}-\mathrm{Hg}$ solid solutions and intermetallic alloys in the rodingites of the Zolotaya Gora gold deposit (Urals, Russia) / V.V. Murzin, K.V. Chudnenko, G.A. Palyanova, D.A. Varlamov, E.A. Naumov, F. Pirajno // Ore Geology Reviews. - 2018. - V. 93. - P. 81-97.

12. Новые данные по кристаллохимии и свойствам природных интерметаллических соединений системы медь-золото М.И. Новгородова, А.И. Цепин, А.И. Горшков, И.М. Кудревич, Л.Н. Вяльсов // Записки Всесоюзного минералогического общества. - 1977. - Ч. 106. - Вып. 5. - С. 540-552.

13. Сульфидная и благороднометалльная минерализация в хромовых рудах Латоргинско-Кершорской площади ВойкароСыньинского массива (Полярный Урал) / Р.И. Шайбеков, С.К. Кузнецов, М.М. Гайкович, С.С. Шевчук // Литосфера. 2015. - № 1. - С. 75-85.

14. Медно-золото-палладиевая минерализация в ультрабазитах Полярного Урала / С.К. Кузнецов, С.А. Онищенко, В.Г. Котельников, В.Н. Филиппов // Доклады Академии наук. 2007. - T. 414. - № 1. - С. 67-69.

15. Кудрявцева А.И., Кудрявцев В.И. Проявление медистого и серебристого золота в благороднометалльном оруденении Южно-Тувинского гипербазитового комплекса // Состояние и освоение природных ресурсов Тувы и сопредельных регионов Центральной Азии. Геоэкология природной среды и общества. - Кызыл: ТувИКОПР СО РАН, 2003. - С. 45-48.

16. Жмодик С.М., Миронов А.Г., Жмодик А.С. Золотоконцентрирующие системы офиолитовых поясов (на примере СаяноБайкало-Муйского пояса). - Новосибирск: Изд-во «Гео», 2008. -304 c

17. Дамдинов Б.Б. Нетрадиционные типы благороднометалльной минерализации в офиолитах Восточно-Саянского и Джидинского поясов: автореф. дис. ... канд. геол. минерал. наук. Улан-Удэ, 2004. - $24 \mathrm{c}$.

18. Григорьева А.В., Дамдинов Б.Б., Служеникин С.Ф. Рудная минерализация в ультрабазитах и метасоматитах ОспинскоКитойского массива (Восточный Саян) // Геология рудных месторождений. - 2018. - Т. 60. - № 2. - С. 141-163.

19. Knight J., Leitch C.H.B. Phase relations in the system $\mathrm{Au}-\mathrm{Cu}-\mathrm{Ag}$ at low temperatures, based on natural assemblages // Canadian Mioneralogist. - 2001. - V. 39. - P. 889-905.

20. Cerny P. Comments on serpentinization and related metasomatism // The American Mineralogist. - 1968. - V 53. - P. 1377-1385.

21. Coleman R.G. Serpentinites, rodingites and tectonic inclusions in Alpine-type mountain chains // Geological Society of America Special Paper. - 1963. - V. 73. - $130 \mathrm{p}$

22. Gold-bearing rodingites of the Agardag ultramafic massif (South Tuva, Russia) and problems of their genesis / V.V. Murzin, G.A. Palyanova, D.A. Varlamov, S.N. Shanina // Geology of Ore Deposits. - 2020. - V. 62. - № 3. - P. 204-224.

23. Sundman B., Fries S., Oates W. A thermodynamic assessment of the Au-Cu system // Calphad. - 1998. - V. 22. - P. 335-354.

24. Muraoka H. Serpentinization reaction responsible for rodingite formation of tha Ashidachi ultramafic complex, Southwest Japan // The Journal of the Japanese Association of Mineralogists, Petrologists and Economic Geologists. - 1985. - V. 80. - № 10. P. 413-428.

25. Ковалев С.Г., Черников А.П., Бурдаков А.В. Первая находка самородного золота в хромитах массивов Крака (Южный Урал) // Доклады академии наук. - 2007. - Т. 414. - № 3. C. 364-367.

26. Гаськов И.В. Главные элементы-примеси самородного золота и связь их с условиями его образования на примере месторождений складчатых поясов Азии // Геология и геофизика. 2017. - T. 58. - № 9. - C. 1359-1376.

27. Morphogenesis and composition of native gold in the Chelopech volcanic-hosted $\mathrm{Au}-\mathrm{Cu}$ epithermal deposit, Srednogorie zone, Bulgaria / I.K. Bonev, T. Kerestedjian, R. Atanassova, C.J. Andrew // Mineralium Deposita. - 2002. - V. 37. - P. 614-629.

Поступила 30.09.2020 2.

\section{Информация об авторах}

Юричев А.Н., кандидат геолого-минералогических наук, доцент кафедры петрографии геологогеографического факультета Национального исследовательского Томского государственного университета. 
UDC 553.461:549.28

\title{
ACCESSORY GOLD-SILVER MINERALIZATION FROM CHROMITITES OF KHARCHERUZ ULTRAMAFIC MASSIF (THE POLAR URALS)
}

\author{
Alexey N. Yurichev, \\ juratur@sibmail.com \\ National Research Tomsk State University, \\ 36, Lenin avenue, Tomsk, 634050, Russia.
}

\begin{abstract}
The relevance of the work is caused by weakly elaboration of mineralogical aspects of ultramafic restitic massifs, which does not allow their generalization at mineralogical level and restoration of complete history of their formation and transformation, as well as solution of number of controversial questions of petrology of these objects. The mineralogy of accessory ore mineralization from restitic ultramafites is poorly studied direction.

The main aim of the research is to study the accessory gold-silver mineralization in massive chromitites of Kharcheruz ultramafic massif of the Polar Urals, reconstruction of mechanism of its formation.

Methods: study of ore mineralization in polished sections using a polarizing microscope AxioScope Carl Zeiss; determination of chemical composition of ore mineralization by the method of X-ray spectrum microanalysis using scanning electron microscope Tescan Mira 3 LMU with energy-dispersive spectrometry UltimMax100 (Oxford Instruments).

The results. For the first time in medium- and densely disseminated chromitites of Kharcheruz ultramafic massif of the Polar Urals, accessory gold-silver mineralization was diagnosed, represented by three-component solid solution $\mathrm{Au}-\mathrm{Cu}$-Ag, corresponding in chemical composition to cuprous gold (cuproauride), and silver sulphide - acanthite $\left(\mathrm{Ag}_{2} \mathrm{~S}\right)$. Formation of revealed acanthite was obviously associated with superimposed metamorphic processes of transformation of original ultrabasic rocks. However, question of the genetic nature of identified $\mathrm{Au}-\mathrm{Cu}-\mathrm{Ag}$ three-component natural triad is not so unambiguous and requires additional, more in-depth study. It is not excluded that the revealed finds of cuprous gold directly in chromitites may belong to primary mantle type, in genesis of which metamorphic crustal processes associated with borrowing of metals dispersed in restite ultramafic rocks or host rocks of frame did not play any significant role. This is also evidenced by close composition of revealed cuproauride with cuprous gold from the chromitites of Voikaro-Synyinsky massif, which along with Kharcheruz massif is a part of the Khadatinsky ophiolite belt and, apparently, has common deep mantle source.
\end{abstract}

\section{Key words:}

The Polar Urals, Kharcheruz massif, restitic ultramafites, chromitites, Au-Cu-Ag alloy, acanthite, chemical composition, genesis.

The research was carried out within the grant of the decree of the Government of the Russian Federation (09.04.2010 no. 220) by the agreement with the Ministry of Education and Science of the RF, 20.02.2017 no. 14.Y26.31.0012.

\section{REFERENCES}

1. Murzin M.V. Zolotoe orudenenie $\mathrm{v}$ ultramafitakh Urala [Gold mineralization in ultramafites of the Urals]. Ultrabazit-bazitovye kompleksy skladchatykh oblastey $i$ svyazannye s nimi mestorozh deniya: sbornik trudov konferentsii [Ultrabasite-basic complexes of folded regions and associated deposits. Proc. of conference]. Ekaterinburg, 2009. pp. 61-64.

2. Jones R.S. Gold in igneus, sedimentary and metamorphic rocks. Geological survey circular 610. Washington, United States Department of the Interior, 1969. $28 \mathrm{p}$.

3. Murzin V.V., Sustavov S.G., Mamin N.A. Zolotaya i platinoidna ya mineralizatsiya rossypey Verkh-Neyvinskogo massiva alpinotipnykh giperbazitov (Sredniy Ural) [Gold and platinoid mineralization of placers of the Verkh-Neyvinsky massif of alpinetype hyperbasites (Middle Urals)]. Ekaterinburg, UGGGA Publ., $1999.93 \mathrm{p}$

4. Chernyshov A.I., Yurichev A.N. The structural evolution of dunite and chromite ore from the Kharcheruz massif, the Polar Urals. Geotectonics, 2016, vol. 50, no. 2, pp. 196-208.

5. Yurichev A.N., Chernyshov A.I. Chromitites of Kharcheruz block of Syum-Keu massif: ore composition and genesis (Polar Ural). Bulletin of the Tomsk Polytechnic University. Geo Assets Engineering, 2016, vol. 327, no. 8, pp. 6-16. In Rus.

6. Yurichev A.N., Chernyshov A.I., Korbovyak E.V. Platinumbearing chromitites in the Kharcheruz ultramafic massif (the Polar Urals): new data. Proceedings of the Russian Mineralogical Society, 2020, vol. 149, no. 3, pp. 38-53. In Rus.

7. Reed S.J.B. Electron microprobe analysis and scanning electron microscopy in geology. N.Y., Cambridge University Press, 2005. $189 \mathrm{p}$.
8. Yurichev A.N. Aktsessornye sulfidy i arsenidy iz khromititov Ergakskogo ultramafitovogo massiva, Zapadny Sayan [Accessory sulphides and arsenides from chromitites of Ergaksky ultramafic massif, Western Sayany area]. Rudy i metally, 2019, no. 3, pp. 71-79.

9. Yurichev A.N., Chernyshov A.I. New ore minerals from the Kingash ultramafic massif, Northwestern Eastern Sayan. Geology of Ore Deposits, 2017, vol. 59, no. 7, pp. 626-631.

10. Oen I.S., Kieft C. Nickeline with pyrrhotite and cubanite exsolutions, $\mathrm{Ni}-\mathrm{Co}$ rich loellingite and an $\mathrm{AuCu}$ alloy in $\mathrm{Cr}-\mathrm{Ni}$ ores from Beni-Bousera, Morocco. Neues Jahrbuch Fur Mineralogie, Monatshefte, 1974, pp. 1-8.

11. Murzin V.V., Chudnenko K.V., Palyanova G.A., Varlamov D.A., Naumov E.A., Pirajno F. Physicochemical model of formation of $\mathrm{Cu}-\mathrm{Ag}-\mathrm{Au}-\mathrm{Hg}$ solid solutions and intermetallic alloys in the rodingites of the Zolotaya Gora gold deposit (Urals, Russia). Ore Geology Reviews, 2018, vol. 93, pp. 81-97.

12. Novgorodova M.I., Tsepin A.I., Gorshkov A.I., Kudrevich I.M., Vyalsov L.N. Novye dannye po kristallokhimii i svoystvam prirodnykh intermetallicheskikh soedineniy sistemy med-zoloto [New data on crystal chemistry and properties of natural intermetallic compounds of copper-gold system]. Zapiski Vsesoyuznogo mineralogicheskogo obshchestva, 1977, vol. 106, no. 5, pp. 540-552

13. Shaybekov R.I., Kuznetsov S.K., Gaykovich M.M., Shevchuk S.S. Sulfidnaya i blagorodnometallnaya mineralizatsiya v khromovykh rudakh Latorginsko-Kershorskoy ploshchadi Voykaro-Syninskogo massiva (Polyarny Ural) [Sulphide and noble metal mineralization in chromium ores of Latorginsko-Kershorskaya area of the Voikaro-Synyinsky massif (the Polar Urals)]. Litosfera, 2015, no. 1, pp. $75-85$.

14. Kuznetsov S.K., Filippov V.N., Onishchenko S.A., Kotelnikov V.G. Copper-gold-palladium mineralization in ultrabasic 
rocks of the Polar Urals. Doklady Earth Sciences, 2007, vol. 414 no. 1, pp. 501-503.

15. Kudryavtseva A.I., Kudryavtsev V.I. Proyavlenie medistogo i serebristogo zolota $\mathrm{v}$ blagorodnometallnom orudenenii YuzhnoTuvinskogo giperbazitovogo kompleksa [Manifestation of cuprous and silvery gold in precious metal mineralization of the SouthTuva hyperbasite complex]. Sostoyanie i osvoenie prirodnykh resursov Tuvy $i$ sopredelnykh regionov Tsentralnoy Azii. Geoekologiya prirodnoy sredy $i$ obshchestva [State and development of natural resources of Tuva and adjacent regions of Central Asia. Geoecology of natural environment and society]. Kyzyl, TuvIKOPR SO RAN, 2003. pp. 45-48.

16. Zhmodik S.M., Mironov A.G., Zhmodik A.S. Zolotokontsentriruyushchie sistemy ofiolitovykh poyasov (na primere SayanoBaykalo-Muyskogo poyasa) [Gold-concentrating systems of ophiolite belts (on example of Sayan-Baikal-Muisky belt)]. Novosibirsk, Geo Publ., 2008. 304 p.

17. Damdinov B.B. Netraditsionnye tipy blagorodnometallnoy mineralizatsii $v$ ofiolitakh Vostochno-Sayanskogo $i$ Dzhidinskogo poyasov. Avtoreferat Dis. Kand. nauk [Unconventional types of noble metal mineralization in ophiolites of East-Sayansky and Dzhidinsky belts. Cand. Diss. Abstract]. Ulan-Ude, 2004. 24 p.

18. Grigoreva A.V., Sluzhenikin S.F., Damdinov B.B. Ore mineralization in ultramafic and metasomatic rocks of the Ospin-Kitoi massif, Eastern Sayan. Geology of Ore Deposits, 2018, vol. 60, no. 2, pp. 121-141.

19. Knight J., Leitch C.H.B. Phase relations in the system $\mathrm{Au}-\mathrm{Cu}-\mathrm{Ag}$ at low temperatures, based on natural assemblages. Canadian Mioneralogist, 2001, vol. 39, pp. 889-905.
20. Cerny P. Comments on serpentinization and related metasomatism. The American Mineralogist, 1968, vol. 53, pp. 1377-1385.

21. Coleman R.G. Serpentinites, rodingites and tectonic inclusions in Alpine-type mountain chains. Geological Society of America Special Paper, 1963, vol. 73, $130 \mathrm{p}$.

22. Murzin V.V., Palyanova G.A., Varlamov D.A., Shanina S.N. Gold-bearing rodingites of the Agardag ultramafic massif (South Tuva, Russia) and problems of their genesis. Geology of Ore Deposits, 2020, vol. 62, no. 3, pp. 204-224.

23. Sundman B., Fries S., Oates W. A thermodynamic assessment of the $\mathrm{Au}-\mathrm{Cu}$ system. Calphad, 1998, vol. 22, pp. 335-354.

24. Muraoka H. Serpentinization reaction responsible for rodingite formation of tha Ashidachi ultramafic complex, Southwest Japan. The Journal of the Japanese Association of Mineralogists, Petrologists and Economic Geologists, 1985, vol. 80, no. 10, pp. 413-428.

25. Kovalev S.G., Chernikov A.P., Burdakov A.V. First finding of native gold in chromites from rock massifs of Kraka (Southern Urals). Doklady Earth Sciences, 2007, vol. 414, no. 1, pp. 526-529.

26. Gaskov I.V. Major impurity elements in native gold and their association with gold mineralization settings in deposits of Asian folded areas. Russian Geology and Geophysics, 2017, vol. 58, no. 9, pp. 1080-1092.

27. Bonev I.K., Kerestedjian T., Atanassova R., Andrew C.J. Morphogenesis and composition of native gold in the Chelopech volcanichosted $\mathrm{Au}-\mathrm{Cu}$ epithermal deposit, Srednogorie zone, Bulgaria. Mineralium Deposita, 2002, vol. 37, pp. 614-629.

Received: 30 September 2020.

\section{Information about the authors}

Alexey N. Yurichev, Cand. Sc., associate professor, National Research Tomsk State University. 